\title{
A WORLD ECONOMIC FORUM PERSPECTIVE ON THE QUADRUPLE HELIX MODEL OF INNOVATION
}

\author{
R.J. Steenkamp ${ }^{1 *}$
}

\section{ARTICLE INFO}

Article details

Submitted by authors 23 Jan 2020

Accepted for publication 16 Sep 2020

Available online $\quad 14$ Dec 2020

\section{Contact details}

Corresponding author

rigardtrapsix@gmail.com

\section{Author affiliations}

1 Department of Operations Management, University of South Africa, South Africa

\section{ORCID® identifiers}

R.J. Steenkamp

https://orcid.org/0000-0003-4748-0817

DOI

http://dx.doi.org/10.7166/31-4-2295
The fourth industrial revolution is a relatively recent phenomenon, underpinned by multiple forces, and thus characterised by both innovation and complexity. Such characteristics bring into play several new concepts that affect societies, ecosystems, leadership, and management in different ways. The need for a model to explain the dynamics of the fourth industrial revolution seems evident from the scope, velocity, and speed of new technologies related to the fourth industrial revolution phenomenon. The quadruple helix model of innovation offers possibilities of bringing together the interplay of multiple concepts both to clarify and to simplify the primary dimensions of the fourth industrial revolution. This article examines these dimensions, and shows how the quadruple helix model potentially connects four movements: triple helix ecosystems, triple management theory, upscaling agility, and epochal society. To review the quadruple helix model, the study employs a three-phased strategy that combines secondary literature sources. This includes, as a prime focus, a perspective from the World Economic Forum as an expression of a prominent and expert view.

\section{OPSOMMING}

Die vierde industriële revolusie is ' $n$ relatiewe nuwe verskynsel onderlê deur verskeie kragte wat beide innoverend en kompleks is. Hierdie eienskappe bring verskeie nuwe konsepte na vore wat gemeenskappe, ekostelsels, leierskap en bestuur op verskeie maniere affekteer. Die behoefte aan 'n model wat die dinamika van die vierde industriële revolusie verduidelik blyk nodig te wees in die lig van die omvang en spoed van nuwe tegnologieë wat aan die revolusie verwant is. Die viervoudige heliks model van innovasie stel moontlikhede voor om die wisselwerking van verskeie konsepte van die revolusie te verhelder en te vereenvoudig in terme van die primêre dimensies. Hierdie artikel ondersoek hierdie dimensies, en dui aan hoe die viervoudige heliks model vier kragte, naamlik, drievoudige heliks ekostelsels, drievoudige bestuursteorie, vergrotingsratsheid, en die tydvakskeppende gemeenskap verbind. 'n Drie-fase strategie, wat sekondêre literatuurbronne gekombineer het, is gevolg om die viervoudige heliks model te hersien. Dit sluit, as hoof fokuspunt, 'n beduidende en ingeligte oorsig vanuit die perspektief van die Wêreld Ekonomiese Forum in.

\section{INTRODUCTION}

The notion of innovation is an important concern for a progressive society in respect of incremental, disruptive, and other types of improvements and new inventions. The disruptions caused by Industry 4.0, referred to as 'the fourth industrial revolution' (FIR) in this article, also point to how the concept might be understood. This uncertainty is one reason why models, pillars, and frameworks attempt to clarify and simplify the complexity of this disruptive but innovative social phenomenon. Viljoen, Vermeulen and Pretorius [1], for instance, used the nine-pillar model to explain the movement, while Roblek, Meško and Krapež [2] provided a conceptual model of the complexity of the FIR to synthesise its known theory and practices. Owing to the paucity of literature on models of the FIR [3], and in search of a benchmark, this article explores the recent quadruple helix $(\mathrm{QH})$ model of innovation for the FIR [4]. The QH model of 
innovation suggests possibilities of bringing together the interplay of multiple complex concepts both to clarify and to simplify the innovation of the FIR. The model does not claim to be finally validated, and this study uses more secondary sources for this purpose. Among others, the World Economic Forum (WEF) is used to express a prominent and expert view. The model, with its four primary dimensions (Figure 1) or streams and sub-dimensions, represents a scholarly contribution, but seems open to improvement through careful analysis, review, and validation.

The FIR phenomenon, which is judged to affect entire societies, presents vast opportunities if aligned with the correct mentality, suitable tools, and the positive disruptions it entails. Yet, within workspaces, new leaders will need to adapt to the growing digital economy related to the FIR. New business models and tools will revolutionise workplace efficiency and the ability to collaborate with multiple stakeholders, no matter where they are situated. Industrial engineers and operations managers are already bombarded by new devices, such as apps and gadgets of the FIR toolbox, smart factories with net shape manufacturing, intelligent systems engineering (ISE), and the astronomical wealth of available data. Also, organisations are becoming smarter and, as such, exponential in nature and thus in need of leaders and managers who can exploit a culture of change and innovation. The challenge is to bring all these concepts together in a model to help leaders and organisations to understand the FIR, with its accompanying leadership and management concepts, better.

To understand innovation in its broadest context, the triple helix (TH) concept is used in the QH model, describing how the business world engages with ever-growing innovation ecosystems. Part of this innovation ecosystem is the integral ingredient of industry (III) - the entrepreneurial university, referred to as University 4.0, which is part of Industry 4.0. Schwab [5], founder and chairperson of the World Economic Forum (WEF), notes the importance of cooperation among all societal stakeholders - business, academia, and government. This cooperative effort is a primary dimension of the model defined as the 'triple helix ecosystem'. Leaders who cooperate in working towards this ecosystemic ideal will need to be creative decision-makers, not caught up in traditional linear thinking.

The need for a model is advocated by a white paper of the WEF [6] that notes how multiple underlying forces of the FIR have ushered in a new economy. The phenomenon is characterised by a combination of confusion, optimism, and fear, causing different philosophical viewpoints to call for model clarity. The conservative viewpoint is one that embraces fundamental industrial engineering progress, defined as 'technology capability'. Whereas this view is neutral about a FIR, regarding innovation as the normal progression of the discipline leading to creative technology management and state-of-the-art operations systems, the idealistic view of the FIR holds promises of a prodigious utopia with radiance and revelry. Some even visualise exponential organisations without the need for quality management owing to their excellent ability to achieve perfection. Makoni [7] from the Department of Finance, Risk Management and Banking (University of South Africa) recently reported how digital finance will eliminate poverty in Africa. However, such aggressive promotion of the FIR will not bring heaven on earth. The fact remains that the disruptive forces of the FIR can be felt across most organisations as unprecedented technological advances produce seismic shifts. These are amplified by associated global trends, such as increasing environmental constraints and rising inequality [6].

Glven this background, this article reports on a critical review of the $\mathrm{QH}$ model. The study involved a literature review, recent conference contributions, and the use of secondary sources from the WEF as predominant benchmarks to validate and improve the $\mathrm{QH}$ model further.

\section{THE PROBLEM STATEMENT}

The previous section introduced the FIR as a complex phenomenon in need of a model to clarify its identity. The recent $\mathrm{QH}$ model can be regarded as a scholarly contribution to the paucity of the literature. Although this model seems to offer a significant contribution, it may need further validation owing to its iterative nature. While the $\mathrm{QH}$ model connects and simplifies the forces of the FIR in terms of four primary dimensions, a deeper comprehension of the the primary sub-revolutions of the model is necessary, as well as the leadership and management theories that underpin the FIR.

\section{METHODOLOGY}

In the study reported here, the method of enquiry comprised a systematic review of secondary narrative data related to innovation concepts and practical examples, including the views of experts contained in 
two reports by the WEF. Morgan [8] supports the cautious distinction between qualitative and quantitative research with reference to the 'indistinguishability thesis'. Thus this investigation drew on secondary data from a range of sources on innovation concepts and narrative data. Saunders, Lewis and Thornhill [9] classify multiple types of secondary data into categories such as documentary, multiple source publications (such as popular literature, newsletters), longitudinal text, published works, and conference proceedings that are available in the public domain. Such sources were used in the following three phases:

A. Developments related to the FIR indicating the need of a model.

B. A holistic review of the $\mathrm{QH}$ model substantiated.

C. A World Economic Forum perspective on the $\mathrm{QH}$ model.

A model represents a system that is constructed to study or guide the system or sub-system. A conceptual framework usually provides the initial way to organise a topic, but it is not as powerful as a model for depth and phases of validation. Research on models is valid if it is a true account of the phenomenon and if the eventual accuracy of the model can be described in terms of degrees of warrantability. It is important in scholarly research for experts to substantiate and validate models [10]. Accordingly, the review in the third investigative phase of the reported study was based on the white paper report of the World Economic Forum (WEF) and the report of the world-renowned economist Klaus Schwab, founder and executive chairman of the WEF. Schwab is uniquely placed to synthesise the experiences and views of experts and the leaders of the world's largest businesses. The reports were thematically analysed to review and improve the $\mathrm{QH}$ model. Plowright [10] notes the importance of disseminating or disentangling the numerous theoretical points of view and making sense of this for a particular study. In the study reported here, this process has led to the further validation of the QH model of innovation for the FIR and to recommendations for improvements.

\section{RESULTS}

The results are presented in the three phases mentioned above: general developments of the FIR, a holistic review of the $\mathrm{QH}$ model, and an expert perspective on the model, based on the WEF.

\section{A. Developments related to the FIR}

Currently, industry-specific developments and specific FIR tools related to data storage, quality monitoring, and touch tracking software are providing an explosion of new data. Digital computing and electronic communication have now developed into artificial intelligence systems. The swelling deluge of data is a sub-revolution on its own, and big data sets will enable operations to do things that were previously impossible. This includes mobile billboard advertising and affordable loT for any industry.

Industry-specific developments include a revolution for freight from road to rail, while for the mining sector, Arnoldi [11] and Parker [12] indicate how the interoperability of mines will be improved using blockchain technology initiatives to trust and analyse data better using cryptography. These 'digital mines' [13] will use new scheduling tools for dynamic agility [14]. Mahendra and Farizal [15] established a framework to integrate loT into the healthcare industry, while Santos, Basto, Alcalá, Frazzon and Azevedo [16] designed a system composed of a simulator and an loT platform with the capability of collecting realtime data from the shop floor to support decision-making.

The operations management discipline develops by using the computing power of modern technologies to create a world of artificial intelligence. While Amankwa [17] indicates how autonomous robots, augmented reality, additive manufacturing, and cloud computing are combined with standard practices, Sartal and Llach [18]) show how FIR technologies significantly reinforced the capacity of lean manufacturing to improve multisector plant performance in six European countries. In addition, Mouček [19] explored how Czech companies can improve their access to digitisation, and Chen, Su and Dong [20] used computational intelligence to solve process optimisation problems. Viljoen, Vermeulen and Pretorius [1] reviewed the extent of the disruptive nature of the FIR, showing how a multitude of exponential improvements can be realised for the early adopters of a digital strategy. This has led to the design of an operations system framework based on integrated lean six-sigma (LSS) for the automotive industry. From these few examples it becomes evident that the QH model should indicate how digitisation connects the forces of innovation from the virtual and physical worlds. It is clear that the interoperability of systems gives process intelligence a new meaning. 
Another example of the $\mathrm{QH}$ model is the development of entrepreneurial universities using triple helix (TH) ecosystems. Benesova, Hirman, Steiner and Tupa [21] point out how the FIR will increase productivity and how the higher education qualifications of students will change their employability.

A model such as the $\mathrm{QH}$ (discussed in sections $\mathrm{B}$ and $\mathrm{C}$ ) must ideally bring together these concepts associated with the FIR.

B. A holistic review of the quadruple helix model

This section summarises the QH model (illustrated in Figure 1) and provides a holistic review of it. A further review will be given in section $\mathrm{C}$. With only four dimensions, it may seem as if the model oversimplifies the FIR; however, each of these 'streams' or 'movements' also entails multiple sub-dimensions (concepts).

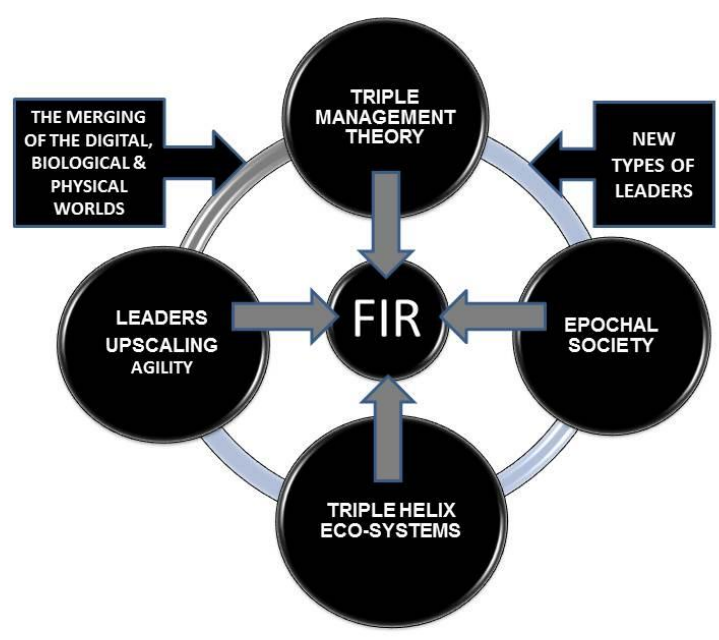

Figure 1: The adapted quadruple helix model of innovation for the FIR

The QH concept was initially suggested by Carayannis and Campbell [22] in respect of the 21st century fractal innovation ecosystem. It emphasises the co-existence and co-evolution of different knowledge paradigms. Cavallini, Soldi, Friedl and Volpe [23] also refer to the QH concept to accelerate the transfer of innovation and research results to society, while Daemmrich [24] emphasises the interplay, integration, and cross-functional cooperation between innovation systems across scientific disciplines.

The TH concept of the inter-related roles of engagement by academia, government, and business (as the three triple helix actors) is fundamental to the QH concept. The original QH model adds a fourth component to the TH framework of interaction - namely, civil society - to bridge the gaps between innovation and society. Modern society is described as 'epochal society' in the QH model. Leydesdorff [25] provides more configurations of the TH model between government, university, and business. Another perspective on the $\mathrm{QH}$ model is a new kind of management competence (triple management theory) and a new kind of leadership (adaptive, agile, and resilient leadership). The 'triple' concepts relate to modern exponential organisations in respect of the triple bottom line (3BL) and triple management theory (TMT).

The four dimensions of the $\mathrm{QH}$ model focus on a new type of knowledge management (KM) - a characteristic of the intelligent society that is strongly linked with TH ecosystems. The epochal society is inherently part of the triple helix (TH) ecosystems, but is dealt with as a separate movement. 'Upscaling agility and resilience' refers to adaptive leadership as a core skill that is needed in the FIR. This skill implies agile business process management (BPM) for quick and effective reaction to internal and external events.

Leaders of innovation will need unique talent and skills to manage the smart operations of exponential organisations. Raheem [26] refers to TMT for agility, technology interoperability, and flexibility, specifically for process changes caused by smart era developments and revolutions. The TMT system is a combination of 'managements', including business process management that would lead to the effective use of resources, structural communication, flexibility (dynamic re-planning), building new knowledge, and effective teamwork [26]. TMT therefore supports process intelligence, technology flexibility for interoperability and workflow orchestration by means of workflow management systems. Linked to 
Raheem's work, Braccini and Margherita [27] shared a case study showing how FIR applications support the triple bottom line by improving the entire operations system.

In the previous section it was noted that the $\mathrm{QH}$ model should indicate how digitisation connects the forces of innovation. The large circle in the QH model (Figure 1) connects the primary dimensions, but it may also represent the bigger picture of organisations that are able to combine the digital, physical, and biological worlds that often succeed in disrupting entire industries and their related systems of production [5]. This is another synergetic force to reckon with, as Caruso [28] predicts a fusion of technologies, thus blurring the lines between the physical, digital, and biological spheres. It also illustrates the global arrival of velocity, scope, exponential pace, and systems impact. It further dissolves the boundaries between industries, institutions, and stakeholders. Fast-moving competitors provoke the traditional silos, and businesses create disruptive ways of combining products and services.

\subsection{The four dimensions of the quadruple helix model}

This part of section B briefly summarises the four dimensions of the $\mathrm{QH}$ model. The interplay and relationships of the concepts are reviewed. Suggestions for improvement are made in section $\mathrm{C}$.

\subsubsection{The triple helix (TH) ecosystems}

Etzkowitz [29] advocated a revolution based on academic and industry relations in terms of a sociological paradigm for economic development. An integrative view of academic entrepreneurship and innovation is provided by Soudien [30], Pavlin, Kesting and Baaken [31], and Van der Duin [32]. The QH model places a major emphasis on university-business cooperation (UBC) and its engagement with government. Recently, Eberl [33] has referred to 100 global business leaders who have discovered the number one secret to be the ability to build strategic alliances across key audiences: peers within their industry, innovators across different industries, and global influences. Also, Galán-Muros [34] from the University-Industry Innovation Network (UIIN) indicates how collaboration between the worlds of science and business is highly beneficial for innovation. Meerman [35], the CEO of the UIIN, consults universities about TH engagement, and their UIIN Newsletter [36] frequently provides related updates.

The Triple Helix Association (www.triplehelixassociation.org) originated at Stanford University, while the Massachusetts Institute of Technology (MIT) is a benchmark for TH consultation. The University of Stanford is a benchmark in UBC with a PoP (professors of practice) system that entails (1) the forward linear concept (faculty entrepreneurs working 50 per cent in industry) and (2) the reverse linear concept (industry entrepreneurs with PhDs moving 50 pec cent part-time to academia) (www.triplehelix.net).

Reischauer [37] refers to this movement as 'institutionalised innovation systems'. The TH vision challenges traditional ways of innovation, encouraging crossing the borders of the spheres of society [38]. Universities will change dramatically in the face of the FIR. In this regard, the UIIN Newsletter [36] refers to the work by Balzhan Orazbayevay entitled Future of universities thoughtbook. Intrapreneurship within the academy can be regarded as a revolution of its own in terms of innovative outcomes, valorisation, synergy, and organisational development [39], [16], [40], [41], [42], [43], [44].

Excellent academia tends to be entrepreneurial; and Van Looy, Ranga, Callaert, Debackere and Zimmerman [45] indicate how scientific performance and entrepreneurial activity in academia promote its research outputs. Van Looy et al. [45] state that, as opportunities increase, this interaction becomes more significant, pointing towards a Matthew effect.

\subsubsection{Epochal society}

The WEF [6] emphasises the responsibility of FIR advocates towards society, and Adams and Mpofu [46] provide a review of the literature on the social reality of the FIR. Modern society has a stronger voice in terms of a knowledge society, social ergonomics, and a service economy. The modern social-technical world involves mega-changes, mega-cities, and mega-technology. Corporate social responsibility (CSR) has taken on a new meaning; so this dimension of the $\mathrm{QH}$ model is discussed separately from the $\mathrm{TH}$ ecosystems because the needs, voice, and other characteristics of society are being transformed in several ways. Such changes include grappling with globalisation, environmental issues, impatience with inequality, and a more socially interactive society.

Social media have contributed to a self-centred and sophisticated society that is more involved in the supply chain of things. This society uses all the sources of intelligence in a knowledge-based economy (KBE). Caruso [28] describes this society as virtual, networkingm and connected, with an improved work-life balance. The intelligent society also has higher value-for-money expectations and higher standards for custom products and services [47]. Carayannis and Campbell [22] also refer to a society being part of the emerging fractal knowledge and innovation ecosystem. 
This remotely smart epochal society is increasingly becoming part of engaging organisations and their valueadding processes. Caruso [28] refers to several advantages of this engaged society: balancing small and large companies, blurring boundaries between entities, and increased autonomy, freedom, and creativity. The ambivalences and dichotomies are related to the socialisation of the production process, the social contents of work, and participation in decision-making. Society has therefore become the informal students of the knowledge society, one of the prominent actors of the $\mathrm{QH}$ model.

\subsubsection{Upscaling agility}

The upscaling agility dimension of the $\mathrm{QH}$ model refers to adaptive leadership [6] with a strong focus on agility. The skill and culture of the exponential organisations of the FIR, with innovation inherently part of the DNA, will be agility. Holbeche [47] defines 'agility' as the capacity to respond, adapt, and thrive in a changing environment. Agile leaders will create an agile environment with competent agile teams throughout the enterprise [48]. This skill implies agile business process management (BPM) for effective reaction to internal and external events.

The resiliently agile organisation needs a culture and structure that facilitates change, with willing and able staff. Organisational effectiveness may be a contested science, but it will need re-imaging owing to the demands and opportunities for agility. This dimension of the $\mathrm{QH}$ model needs a new kind of manager. Raheem [26] refers to managers applying TMT for agility, which is discussed next.

\subsubsection{Triple management theory}

The fourth dimension of the $\mathrm{QH}$ model is a practical and realistic one in terms of deploying strategies by competent managers. Competitive organisations strive for the triple bottom line with the arrival of new markets and the velocity, scope, and exponential pace of processes. This demands new skill sets in unique and combined management approaches. As noted in section B, Raheem [26] refers to TMT supporting process intelligence, operational flexibility, technological flexibility, workflow orchestration, and system interoperability. Collaboration between multiple organisations demands TMT, which is a combination of business process management (BPM), adaptive case management (ACM), and human interactive management (HIM), to support change and interoperability.

Process intelligence (and BPM) will therefore obtain a new meaning owing to the drive for high performance in a digital age [49]. BPM is called 'agile' when it is able to react quickly and adequately to internal and external events. Agile BPM requires framing the life cycle of business processes in a new paradigm. Raheem [26] notes that BPM has a wider scope than work-flow management (WFM), and includes process automation, process analysis, and operations management. TMT ensures that information, processes, and technology become sufficiently organic and therefore flexible enough to allow for system interoperability. Kirchmer [50] calls for an upshift, because only a few have their business processes sufficiently under control to realise the potential of their digital initiatives. The author refers to the upshift leading to BPM 4.0, leveraging the power of the internet to enhance process management as a core sub-dimension of TMT.

\section{A World Economic Forum perspective}

This section further validates the $\mathrm{QH}$ model by employing the views of experts from the World Economic Forum (WEF). The four dimensions of the model and its sub-dimensions are reviewed by means of a thematic analysis of Schwab [5] and Schwab [51], as well as a recent WEF (2019) white paper on the core dimensions of the FIR. Suggestions are made at the end of each about how the model could be improved without overpopulating the $\mathrm{QH}$ model.

\section{PRIMARY DIMENSION: LEADERSHIP}

The QH model does not mention leadership separately, but it may include the new types of leadership needed for the FIR. 'Leaders upscaling agility' is clearly highlighted, and refers to adaptive leadership, as stressed by the World Economic Forum [6]. Leadership will undergo a paradigm shift, and entrepreneurial leadership and technology leadership may also be included. Technology for production enters a new paradigm, forging a multi-stakeholder compact to enable the for production workforce. All these leaders of operations will have smart factories that enable workers, so changing the nature of work in production. It will attract talent, involve and engage the production workforce, and reshape the broader enabling environment of production [6].

As indicated by Figure 1, the FIR demands and produces new types of leader; and the large circle in the QH model may also represent the bigger picture of organisations that are able to combine the digital, physical, and biological worlds. Leaders in the biological realm, for example, are needed for healthcare, precision 
medicine, modern agriculture, biofuels, and even the breath-taking (and controversial) innovations related to genetics. All of these new leaders will be futurists who understand and anticipate mega-trends [5] in the biological, physical, and digital worlds.

\section{PRIMARY DIMENSION: TRIPLE HELIX ECOSYSTEMS}

This is a well-described and comprehensive dimension of the $\mathrm{QH}$ model. $\mathrm{TH}$ and the important entrepreneurial university component are clearly addressed. Innovation is a complex and social process, and Schwab [5] confirms the need for academic institutions to be on board with forward thinking. The way to get those in the knowledge industry increasingly involved is through UBC and TH partnerships and by encouraging commercial forms of research. Schwab [5] confirms the TH concept, in which cities (as ecosystems) adopt a new focus on innovation. The speed and breadth of cities in absorbing and deploying technology with agile operations will determine their ability to compete and attract talent. These ecosystems become launching pads for innovative start-ups. The future of cities becoming smart networkdriven entities and regions becoming holistic innovative ecosystems is therefore a concept on its own.

\section{Suggested improvement to the model}

This dimension of the $\mathrm{QH}$ model combines a variety of concepts. One aspect that may need to be increasingly emphasised is TH entrepreneurial leadership. Leadership for innovation means creating the environment and culture to unlock innovation by tapping into people's strengths and aspirations to do meaningful work [6].

The WEF's white paper also highlights technology leadership, which may be the core outcome - and the final outcome - of the entire FIR model (the centre point of Figure 1). This relates strongly to digitalisation, because every business becomes a digital business in a digital economy. The majority of the workforces are not yet ready to work with intelligent technology, and less than half of executives believe that they have the skills and abilities to lead in the digital economy. The following quote by the chairman of Siemens sums it up: "The new digital reality requires a new kind of leadership, one that understands the rules of the digital season, reinvents business from a position of strength, thinks exponentially rather than linearly and develops people to unleash their full potential" [6].

\section{PRIMARY DIMENSION: EPOCHAL SOCIETY}

The WEF has a strong focus on CSR, as does the QH model. The so-called 'me-centered' society sees an emerging self-focused process of individuation, new forms of belonging, connecting, and community. Digital media is connecting people one-to-one and one-to-many in entirely new ways, enabling users to have friendships across distance and time. Schwab [5] confirms the drastic changes in society: its new intelligence, its involvement, and its demands. The organisation becomes a more integral part of society, and innovation is seen as a social process.

More tasks are performed remotely, dramatically increasing the efficiency of society. Social integration is taken to the extreme when designers mix computational design, materials engineering, and synthetic biology to pioneer systems that involve interactions among the human body, the human diet, microorganisms, and the buildings we inhabit. Customers and designers become social teams, while artificial intelligence, human intelligence, and KM become a dexterous force of production. Exponential increases in computing power, with the better use of vast amounts of data, predict new things everywhere such as new drugs, new algorithms, new robots, and even new cultural interests. Devices will become like 'little beings' with voice recognition, talking to computers, anticipating needs, and providing help when required [5].

Morality and identity must be intact when we respond to issues of life itself. Digital technologies are not all new, but they are becoming smarter and more integrated with life. They are transforming societies and the global economy such that it is referred to as 'the second machine age': the world is at an inflection point where the effect of these technologies will manifest with full force, creating unprecedented products and services through automation and innovation [5].

Rising inequality is a significant challenge, and leaders will have to find ways to balance benefits and risks to make the FIR an opportunity for all. Many developing countries fall behind; only 17 per cent of the world has electricity. The FIR will increase the gap between those depending on labour and those who own capital. Other ethical concerns relate to human identity, human privacy, human choice, addiction, dignity, roles, and purpose. 
The social nature of work is already visible as the requirements for skill sets change. A scenario of transactions between a company and a worker owing to the on-demand economy is emerging. The social fabric changes, and employers will use the 'human cloud' of experts to get things done. Work will be broken down into precise assignments, smaller jobs, or temporary projects. The logic of this approach is the availability of virtual clouds all over the world and the elimination of employment hassles.

Although many new jobs are being created, labour substitution is a threat. Mechanically repetitive and precise manual labour is being automated. Schwab [5] lists the many professions that are most or least suitable for automation. This puts the focus on new types of leaders, new types of managers, and the new skill sets of the future, as addressed in the $\mathrm{QH}$ model. The low-risk jobs require human intelligence, creativity (for novel ideas), integration skills, decision-making under uncertainty, and the ability to understand the triple concepts (such as TMT) for the triple bottom-line. Schwab [5] lists the most significant skills demands for 2020, based on the future of jobs, as including cognitive abilities, social skills, system skills, complex problem-solving, and process skills.

\section{Suggested improvement to the model}

The QH model could elaborate on CSR. Schwab [5] emphasises the importance of finding ways to impact families positively. The WEF also brings politics to the fore, expecting leaders proactively to address rising concerns about inequality, social tensions, and the protection of the environment [6].

\section{PRIMARY DIMENSION: LEADERS UPSCALING AGILITY}

Schwab [5] refers to 'agile leaders' as those who continually learn, adapt, and challenge their own thinking and doing. The leaders of the future will need the ability to disrupt their own comfort, as well as their conceptual and operating models. The speed and scale of change will necessitate a similar transformation in how businesses are led, organised, and resourced. If the future of work changes, the future of leadership and management will also change. A deluge of available information should help leaders to respond as agile teams and agile organisations.

In a world of customer experiences, partnerships with society are increasingly at the centre of the digital economy. The ability to respond with real-world data will mean a larger market presence and an integrated customer experience. Cross-industry boundaries also demand the skill to be organic, because major shifts on the demand side are disrupting businesses. Society has become more educated, resulting in new patterns of consumer behaviour that require transparency and engagement. To be customer-centric will therefore need agility at the next level as real-time data and analytics bring a new paradigm to the way that customers are targeted [5].

\section{Suggested improvement to the model}

Figure 1 suggests new types of leaders, but the $\mathrm{QH}$ model could elaborate on adaptive leadership for agility. To keep up with the high velocity, leaders and teams should jettison the 'pilot and perfect' model, leaving them free to experiment rapidly and learn as they go. Agility prepares people for uncertainty, and continuous learning keeps them relevant. Adaptive leadership also implies anticipating disruption and proactively identifying where agility is required in response [6].

\section{PRIMARY DIMENSION: TRIPLE MANAGEMENT THEORY}

The WEF does not use the TMT terminology; however, it refers to new 'management models' that are needed to operate faster and with greater agility. The TMT dimension of the QH model is clearly described as a concept of integrated types of 'managements' such as BPM, ACM and HIM. The concept refers to the management's ability to work with the new types of leader of the FIR (Figure 1). These managers will be in the front-line of applying TMT in the TH ecosystems for the triple bottom-line of exponential organisations. These emerging operating models (with TMT abilities) mean that talent and culture have to be rethought [5].

Future companies will become more open as part of a fluid ecosystem, and leaders will focus on a new type of manager with integrative and dynamic skills. Talent management or 'talentism' will be part of the new work environment, with flexible hierarchies and new ways of managing HR. The new management corps will build all types of capacity into a mode of valorisation and a Matthew effect. The emerging modern workplace will also enable organisations to blend digital and physical experiences to benefit both workers and consumers. 
This study critically reviewed the recent QH model, following the need for model clarity about the FIR identity. The revised model connects and simplifies the forces of the FIR with four primary dimensions and a holistic overview. A review of the $\mathrm{QH}$ model using recent secondary sources confirmed the usefulness of the model, which explains the interplay among the underpinning forces of innovation related to the FIR.

The final phase of the research involved a further refinement of the model by employing prominent views generated from WEF literature and documentation. Although most of the primary dimensions were substantiated, a few model improvement areas were identified. Referring to Figure 1, the centre of the model connects the primary dimensions of the FIR; but it may also represent the bigger picture of organisations being able to combine the digital, physical, and biological worlds within the FIR (suggested in Figure 1). The QH model may further comprise new types of leadership that are needed for the FIR. It may be a separate dimension of the model (suggested in Figure 1), although leadership is assumed to be imbedded in the four primary dimensions. Triple helix (TH) leadership in entrepreneurial leadership is an example, while the WEF's white paper highlights technology leadership as a possible core or final outcome of the entire QH model (the centre point suggested in Figure 1). The QH model also refers to 'upscaling agility'; this dimension could be broadened as 'adaptive leadership', since the FIR causes, accommodates, and anticipates disruption. The challenge would be proactively to identify where agility is required as an appropriate response to disruption [6]. The WEF literature also holds a broader view of an 'epochal society', referring to the role of politics, corporate social responsibility (CSR), and the importance of finding ways to impact families positively.

While the present review points to a measure of usefulness, it is evident that the $\mathrm{QH}$ model needs further validation. It is thus suggested that the model be further improved without compromising the essential purpose of reigning model designs.

\section{REFERENCES}

[1] Viljoen, A.J., Vermeulen, A. \& Pretorius, J.C. 2019. The efficient and precision nature within the cyber physical systems (CPS) and Industry 4.0 technologies in industry operations. Proceedings of the International Conference on Industrial Engineering and Operations Management, Pilsen, Czech Republic, July 23-26. IEOM Society International.

[2] Roblek, V., Meško, M. \& Krapež, A. 2016. A complex view of Industry 4.0. 2016. SAGE Open, April-June, pp. 111. Available at https://us.sagepub.com/en-us/nam/open-access-at-sage. [Accessed October 2019]

[3] Brown, L. 2019. Library Services - University of South Africa, Muckleneuk Campus, Pretoria.

[4] Steenkamp, R.J. 2019. The quadruple helix model of innovation for Industry 4.0. Acta Commercii, $19(1)$, a820. https://doi.org/10.4102/ac.v19i1.820

[5] Schwab, K. 2017. The fourth industrial revolution. London: Portfolio Penguin.

[6] World Economic Forum. 2019. White paper - Leading through the Fourth Industrial Revolution putting people at the centre, January. Cologny/Geneva: World Economic Forum.

[7] Makoni, P. 2019. Digital finance could eliminate poverty in Africa. Let's talk Magazine. College of Economic and Management Sciences, University of Pretoria, November 4.

[8] Morgan, D.L. 2018. Living within blurry boundaries: The value of distinguishing between qualitative and quantitative research. Journal of Mixed Methods Research, 12(3), pp. 268-279.

[9] Saunders, M., Lewis, P. \& Thornhill, A. 2012. Research methods for business students. London: Pearson.

[10] Plowright, P. 2011. Using mixed methods - Frameworks for an integrated methodology. London: SAGE Publications Ltd.

[11] Arnoldi, M. 2019. Mining companies, WEF in responsible sourcing partnership. Mining Weekly, November 8-14, Johannesburg: Creamer Media (Pty) Ltd.

[12] Parker, D. 2019. Blockchain solutions available to African mining. Mining Weekly, November 8-14, Johannesburg: Creamer Media (Pty) Ltd.

[13] Bhowan, T.D. 2019. Digital transformation will benefit African mines. Mining Weekly, November 8-14, Johannesburg: Creamer Media (Pty) Ltd.

[14] Odendaal, N. 2019. Dynamic and agile. Mining Weekly, November 8-14, Johannesburg: Creamer Media (Pty) Ltd.

[15] Mahendra E.A. \& Farizal, M.D. 2019. Internet Of Things based processes improvement of Indonesian hospital. Proceedings of the International Conference on Industrial Engineering and Operations Management, Pilsen, Czech Republic, July 23-2. IEOM Society International.

[16] Santos, R., Basto, J., Alcalá, S.G.S., Frazzon, E. \& Azevedo, A. 2019. Industrial loT integrated with simulation - A digital twin approach to support real-time decision making. Proceedings of the International Conference on Industrial Engineering and Operations Management, Pilsen, Czech Republic, July 23-26. IEOM Society International.

[17] Amankwa, E. 2019. Industrialisation and its impact on operations management development in South Africa: A guess into the fourth industrial revolution. Proceedings of the International Conference on Industrial Engineering and Operations Management, Pilsen, Czech Republic, July 23-26. IEOM Society International. 
[18] Sartal, A. \& Llach, J. 2019. Exploring the potential of new technologies in lean shop-floors: Do Industry 4.0 resources really matter? Proceedings of the International Conference on Industrial Engineering and Operations Management, Pilsen, Czech Republic, July 23-26. IEOM Society International.

[19] Mouček, J. 2019. Digitalization in Industry 4.0: Knowledge management. Proceedings of the International Conference on Industrial Engineering and Operations Management, Pilsen, Czech Republic, July 23-26. IEOM Society International.

[20] Chen, L., Su, C. \& Dong, Y. 2019. Computational intelligence for process optimization in casting industry. Proceedings of the International Conference on Industrial Engineering and Operations Management, Pilsen, Czech Republic, July 23-26. IEOM Society International.

[21] Benesova, A., Hirman, M., Steiner, F. \& Tupa, J. 2019. Requirements for Education 4.0 and study programs within Industry 4.0. Proceedings of the International Conference on Industrial Engineering and Operations Management, Pilsen, Czech Republic, July 23-26. IEOM Society International.

[22] Carayannis, E.G. \& Campbell, D.F.J. 2009. 'Mode 3' and 'quadruple helix': Towards a 21st century fractal innovation ecosystem. International Journal of Technology Management, 46(3/4).

[23] Cavallini, S., Soldi, R., Friedl, J. \& Volpe, M. 2016. Using the quadruple helix approach to accelerate the transfer of research and innovation results to regional growth. European Union Committee of the Regions.

[24] Daemmrich, A. 2017. Invention, innovation systems, and the fourth industrial revolution. Technology \& Innovation, 18(4), March, 257-265(9). National Academy of Inventors. Available at: https://doi.org/10.21300/18.4.2017.257

[25] Leydesdorff, L.J. 2018. Synergy in knowledge-based innovation systems at national and regional levels: The triplehelix model and the fourth industrial revolution. Journal of Open Innovation: Technology, Market and Complexity, 4(16).

[26] Raheem, R.O. 2018. Triple management theory and agility, technology interoperability and flexibility challenges in a specified domain. The IUP Journal of Knowledge Management, 16(2).

[27] Braccini, A.M. \& Margherita, E.G. 2019. Exploring organizational sustainability of Industry 4.0 under the triple bottom line: The case of a manufacturing company. Sustainability, 11, 36. doi:10.3390/su11010036 (MDPI Journal).

[28] Caruso, L. 2018. Digital innovation and the fourth industrial revolution: Epochal social changes? Al \& Society, 33, pp. 379-392. Available at: https://doi.org/10.1007/s00146-017-0736-1

[29] Etzkowitz, H. 1994. Academic-industry relations: A sociological paradigm for economic development. In Evolutionary Economics and Chaos Theory: New Directions in Technology Studies. London: UK, pp. 139-151.

[30] Soudien, C. 2014. Inclusion, innovation and excellence: Higher education in South Africa and its role in social development. South African Journal of Higher Education, 28(3), pp. 907-922.

[31] Pavlin, S., Kesting, T. \& Baaken, T. 2016. An integrative view on higher education and UBC in the light of academic entrepreneurship. European Journal of Education, 51(1). Available at: DOI:10.1111/ejed.12168

[32] Van der Duin, P. 2016. Managing technology, entrepreneurship and innovation. [Blog post]. Available at: https://blog.uiin.org [2016, April 12].

[33] Eberl, N. 2019. FutureScaling: How to build strategic alliances in the era of collaborative co-creation. University Industry Collaboration Indaba: Creating an inclusive innovation ecosystem. Conference papers. Pretoria Sheraton, 16-17 October.

[34] Galán-Muros, V. 2019. University-business cooperation: Education vs research collaboration. University Industry Collaboration Indaba: Creating an inclusive innovation ecosystem. Conference papers. Pretoria Sheraton, 16-17 October.

[35] Meerman, A. 2019. Different types of engaged universities: No one size fits all. University Industry Collaboration Indaba: Creating an inclusive innovation ecosystem. Conference papers. Pretoria Sheraton, 16-17 October.

[36] UIIN newsletter. 2019. University Industry Innovation Network. Science Park. The Netherlands. www.uiin.org; office@uiin.org

[37] Reischauer, G. 2018. Technological Forecasting \& Social Change, 132, pp. 26-33. Available at: https://doi.org/10.1016/j.techfore. 2018.02.012.

[38] Etzkowitz, H. \& Viale, R. 2010. Polyvalent knowledge and the entrepreneurial university: A third academic revolution? Critical Sociology, 3(4), pp. 595-609.

[39] Douglas, E.J. \& Fitzsimmons, J.R. 2013. Intrapreneurial intentions versus entrepreneurial intentions: Distinct constructs with different antecedents. Small Business Economy (Springer Business), 41, 115.

[40] Dovey, K. \& Remback, M. 2015. Invisible practices, innovative outcomes: Intrapreneurship within the academy. Action Learning: Research and Practice, 12(3), 276.

[41] Hecker, A. 2017. The intrapreneurial nature of organizational innovation: Toward a new process model. International Journal of Innovation, 5(3), pp. 375-398. Available at: http://dx.doi.org/10.5585/ijji.v5i3.208

[42] Hofste-Kuipers, M. 2016. How UT became number one in the valorisation ranking of Dutch universities. Paper presented at the University Industry Interaction Conference, Amsterdam, Netherlands, June.

[43] De Silva, M. 2016. Academic entrepreneurship and traditional academic duties: Synergy or rivalry? Studies in Higher Education, 41(12), pp. 2169-2183. Available at: http://dx.doi.org/10.1080/03075079.2015.1029901

[44] Kafile, M. 2018. A framework of intrapreneurship for corporate entrepreneurship: A case study of organisational development. Educor Multdisciplinary Journal, 1(1).

[45] Van Looy., B, Ranga, M., Callaert, J., Debackere, K. \& Zimmerman, E. 2004. Combining entrepreneurial and scientific performance in academia: Towards a compounded and reciprocal Matthew-effect. Research Policy, 33, 425.

[46] Adams, D.Q. \& Mpofu, K.M. 2018. What has Industry 4.0 got to do with us? A review of the literature. Proceedings of the International Conference on Industrial Engineering and Operations Management, Pretoria/Johannesburg, South Africa, October 29 - November 1.

[47] Holbeche, L.S. 2018. Organisational effectiveness and agility. Journal of Organizational Effectiveness: People and Performance, 5(4), pp. 302-313. Available at: https://doi.org/10.1108/JOEPP-07-2018-0044 
[48] Rigby, D.K., Sutherland, J. \& Noble, A. 2018. Agile at scale. Harvard Business Review, May-June, pp. 88-96.

[49] Bruno, G., Dengler, F., Jennings, B., Khalaf, R., Nurcan, S., Prilla, M., Sarini, M., Schmidt, R. \& Rito, S. 2011. Key challenges for enabling agile BPM with social software. Journal of Software Maintenance and Evolution: Research and Practice, 23(4), pp. 297-326. Available at: https://doi.org/10.1002/smr.523

[50] Kirchmer, M. 2018. Enabling high performance in the digital age. Industrial and Systems Engineering Magazine. Institute of Industrial Engineers. Available at: www.iise.org/ISEmagazine

[51] Schwab, K. 2016. The fourth industrial revolution: What it means, how to respond. Available at: https://www. weforum.org/agenda 